\title{
Treatment with placenta-derived mesenchymal stem cells mitigates development of bronchiolitis obliterans in a murine model
}

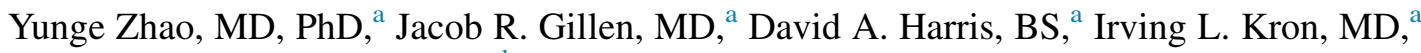 \\ Michael P. Murphy, MD, FACS, ${ }^{b}$ and Christine L. Lau, MD, MBA ${ }^{\mathrm{a}}$
}

\begin{abstract}
Objective: Bone marrow-derived mesenchymal stem cells (MSCs) have shown therapeutic potential in acute lung injury. Recently, placenta-derived human mesenchymal stem cells (PMSCs) have shown similarities with bone marrow-derived MSCs in terms of regenerative capabilities and immunogenicity. This study investigates the hypothesis that treatment with PMSCs reduces the development of bronchiolitis obliterans in a murine heterotopic tracheal transplant model.
\end{abstract}

\begin{abstract}
Methods: A murine heterotopic tracheal transplant model was used to study the continuum from acute to chronic rejection. In the treatment groups, PMSCs or PMSC-conditioned medium (PMSCCM) were injected either locally or intratracheally into the allograft. Phosphate-buffered saline (PBS) or blank medium was injected in the control groups. Tracheal luminal obliteration was assessed on sections stained with hematoxylin and eosin. Infiltration of inflammatory and immune cells and epithelial progenitor cells was assessed using immunohistochemistry and densitometric analysis.
\end{abstract}

Results: Compared with injection of PBS, local injection of PMSCs significantly reduced luminal obliteration at 28 days after transplantation $(P=.015)$. Intratracheal injection of PMSCs showed similar results to local injection of PMSCs compared with injection of PBS and blank medium $(P=.022)$. Tracheas treated with PMSC/ PMSCCM showed protection against the loss of epithelium on day 14, with an increase in P63+CK14+ epithelial progenitor cells and Foxp3+ regulatory T cells. In addition, injection of PMSCs and PMSCCM significantly reduced the number of neutrophils and CD3 + T cells on day 14 .

Conclusions: This study demonstrates that treatment with PMSCs is protective against the development of bronchiolitis obliterans in an heterotopic tracheal transplant model. These results indicate that PMSCs could provide a novel therapeutic option to reduce chronic rejection after lung transplant. ( $\mathrm{J}$ Thorac Cardiovasc Surg 2014;147:1668-77)

Supplemental material is available online.

Lung transplantation is the best therapeutic option for many debilitating pulmonary diseases. Chronic rejection, which manifests histologically as bronchiolitis obliterans (BO), is

From the Division of Thoracic and Cardiovascular Surgery, ${ }^{\mathrm{a}}$ Department of Surgery, University of Virginia Health System, Charlottesville, Va; The Vascular and Cardiac Center for Adult Stem Cell Therapy, ${ }^{b}$ Indiana University School of Medicine, Indianapolis, Ind.

C.L.L. is supported by a grant sponsored by the National Heart, Lung, and Blood Institute (1K08HL094704) and matching funds from the Thoracic Surgery Foundation for Research and Education. I.L.K. is supported by a grant sponsored by the National Institute of Health (5RO1HL092953). J.R.G. and is supported by a training grant under I.L.K sponsored by the National Institute of Health (NIH T32HL007849).

Disclosures: Authors have nothing to disclose with regard to commercial support.

Received for publication July 5, 2013; revisions received Aug 27, 2013; accepted for publication Sept 13, 2013; available ahead of print Nov 6, 2013.

Address for reprints: Christine L. Lau, MD, MBA, Department of Surgery, PO Box 800679, Charlottesville, VA 22908-0679 (E-mail: cl12y@virginia.edu). 0022-5223/\$0.00

Published by Elsevier Inc. on behalf of The American Association for Thoracic Surgery

http://dx.doi.org/10.1016/j.jtcvs.2013.09.041 the single most important cause of late mortality after lung transplantation, affecting up to $50 \%$ of patients 5 years after transplantation. ${ }^{1,2}$ Despite remarkable progress in improving outcomes through the refinement of surgical technique and the use of more effective immunosuppressive regimens, BO still affects most lung transplant recipients by 5 years; no treatment options have shown beneficial effects for preventing or slowing the progress of this disease. ${ }^{1,2}$ Therefore, innovative and effective therapies (such as molecule- and cell-based therapies) to prevent and attenuate the development of BO are urgently needed.

Mesenchymal stem cells (MSCs) originating from the bone marrow have been used as a therapeutic strategy in several in vivo models of acute lung injury, including bleomycin-induced, ${ }^{3}$ intraperitoneal and intratracheal Escherichia coli endotoxin-induced ${ }^{4,5}$ and lipopolysaccharide-induced ${ }^{6}$ acute lung injury. Recent research has provided clear evidence that MSCs have great potential as a cell-based therapy for acute lung injury due to several features, including (1) secretion of multiple paracrine factors, including keratinocyte growth factor, ${ }^{7}$ interleukin (IL)-1 receptor antagonist (IL-1RA), ${ }^{8}$ granulocyte colony-stimulating factor (G-CSF), and granulocyte macrophage colony-stimulating factor 


$$
\begin{aligned}
& \text { Abbreviations and Acronyms } \\
& \text { BO = bronchiolitis obliterans } \\
& \text { DAPI = 4,6-diamidine-2-phenylindole } \\
& \text { dihydrochloride } \\
& \text { G-CSF = granulocyte colony-stimulating } \\
& \text { factor } \\
& \text { GM-CSF = granulocyte macrophage } \\
& \text { colony-stimulating factor } \\
& \mathrm{H} \& \mathrm{E} \quad=\text { hematoxylin and eosin } \\
& \text { HPF = high-power field } \\
& \text { HTT = heterotopic tracheal transplant } \\
& \text { IL } \quad=\text { interleukin } \\
& \text { IL-1RA = interleukin } 1 \text { receptor antagonist } \\
& \text { MSC = mesenchymal stem cells } \\
& \text { PBS = phosphate-buffered saline } \\
& \text { PMSC = placenta-derived human } \\
& \text { mesenchymal stem cells } \\
& \text { PMSCCM }=\text { PMSC-conditioned medium } \\
& \mathrm{TNF}=\text { tumor necrosis factor }
\end{aligned}
$$

(GM-CSF) ${ }^{9}$; G-CSF and GM-CSF are believed to promote the mobilization of endogenous stem cells into the blood circulation; (2) blocking of inflammatory cytokines, such as interferon- $\gamma$, IL-2, IL- $1 \beta$, IL-4, macrophage inflammatory protein-2, and tumor necrosis factor (TNF)- $\alpha,{ }^{3,7}$ all fundamental proinflammatory cytokines involved in lung injury; (3) immunosuppressive effects, by inhibiting the activity of innate and adaptive immune cells ${ }^{10,11}$; (4) alteration of the endothelial and epithelial permeability of the lung ${ }^{5,12}$; (5) reduction of edema by restoring alveolar fluid clearance.

Recently, human placenta-derived MSCs (PMSCs) have been isolated, characterized, and studied by various laboratories. PMSCs not only express common MSC surface markers such as CD11a, CD29, CD44, CD73 CD90, CD105, CD146, CD166, and HLA-ABC but also have the ability to differentiate into adipogenic, chondrogenic, and osteogenic lineages under the proper conditions. ${ }^{13,14}$ Compared with bone marrow-derived MSCs, PMSCs are more easily obtained and are available in large numbers. Because they have similar properties and effects as bone marrow-derived MSCs, they are becoming a promising alternative source of MSCs in basic research and clinical applications. In the recent literature, PMSCs have been shown to have immunosuppressive properties by suppressing the activation and proliferation of $\mathrm{T}$ lymphocytes. ${ }^{15,16}$ In addition, PMSCs show minimal to no immunogenicity. ${ }^{17}$

Because of these unique properties of PMSCs, the present study was designed to explore the use of PMSCs as a novel treatment to prevent the development of $\mathrm{BO}$. We hypothesized that local treatment with PMSCs or PMSCconditioned medium (PMSCCM) suppresses inflammatory and immunologic cascades and reduces the development of BO in a murine heterotopic tracheal transplant (HTT) model.

\section{MATERIALS AND METHODS Culture of Human PMSCs}

PMSCs $^{18}$ were obtained from the laboratory of our collaborator, Dr Michael P. Murphy (Indiana University School of Medicine, Indianapolis, Ind). The PMSCs were grown in Dulbecco's modified Eagle's medium/ F12K (1:1) medium (Gibco BRL, Life Technologies, Rockville, Md) supplemented with $10 \%$ fetal bovine serum and $1 \%$ of penicillin/streptomycin in a humidified incubator containing $5 \% \mathrm{CO}_{2}$ at $37^{\circ} \mathrm{C}$. When the cell density reached $90 \%$ confluence, the conditioned medium was collected and centrifuged at $1000 \mathrm{rpm}$ to remove the debris. After washing with warm $1 \times$ phosphate-buffered saline (PBS), the cells were detached with $0.05 \%$ Trypsin-EDTA and centrifuged at $600 \mathrm{rpm}$. The harvested cells were then washed with $1 \times$ PBS twice. The cells were counted using a Cellometer Auto 2000 (Nexcelom Bioscience LLC, Lawrence, Mass). The cells were diluted in $1 \times \operatorname{PBS}\left(1 \times 10^{7}\right)$ and put on ice until they were injected.

\section{Mice}

The experimental mice were purchased from Jackson Laboratory (Bar Harbor, Maine). The Animal Care and Use Committee at the University of Virginia approved all aspects of the experimental protocol before experimentation. All experimental mice received humane care in accordance with The Principles of Laboratory Animal Care and The Guide for the Care and Use of Laboratory Animals.

\section{Experimental Groups}

The mouse HTT model was used as described previously. ${ }^{19}$ Male $\mathrm{BALB} / \mathrm{c}$ mice were used as donors and C57BL/6 mice as recipients (22$27 \mathrm{~g}$ ). Each recipient mouse received 4 different donor tracheas transplanted subcutaneously. The recipient mice were randomly divided into 6 groups: group 1 , PMSC cells $\left(1 \times 10^{6}\right.$ cell in PBS) were injected locally into the subcutaneous area surrounding the transplanted trachea on day 1 after transplantation (4 recipient mice/time point); group 2, the same volume of PBS was injected locally as a control for group 1; group 3, PMSC cells $\left(1 \times 10^{5}\right.$ cell in PBS $)$ were injected directly into the lumen of the transplanted trachea on day 3 after transplantation (4-7 mice/time point); group 4, the same volume of PBS was injected directly into the lumen of the transplanted trachea on day 3 after transplantation as a control of group 3 (3 mice/time point); group 5, PMSC-CM was injected directly into the lumen of the transplanted trachea on day 3 after transplantation (46 mice/time point); group 6 , the same volume of blank medium was injected directly into the lumen of the transplanted trachea on day 3 after transplantation as a control for group 5 ( 3 mice/time point). The intratracheal injections were performed as previously described. ${ }^{20}$ The recipient mice were killed and the allografts were harvested on day 7, 14, or 28 for histology and immunohistochemical staining.

\section{Histology and Immunohistochemical Staining}

The harvested allograft specimens were immediately fixed in $10 \%$ formalin. After 24 hours, fixed tracheas were embedded in paraffin and sections were stained with hematoxylin and eosin (H\&E) or stained by immunohistochemistry.

Immunohistochemical staining of mouse migratory macrophages and neutrophils. Staining for mouse migratory macrophages and neutrophils was performed as described previously. ${ }^{19,20}$ Briefly, rat antimouse neutrophil antibody (AbD Serotec, Raleigh, NC) and rat antimouse Mac-2 antibody (Accurate Chem, Westbury, NY) were used as primary antibodies. Alkaline phosphatase-conjugated donkey antirat IgG (Sigma, St Louis, Mo) was used as a secondary antibody. The 
signals were detected using Fast Red (Sigma, St Louis, Mo). Purified normal rat IgG (eBioscience Inc, San Diego, Calif) was used for negative controls.

Immunohistochemical staining of mouse $\mathrm{CD3}+\mathrm{T}$ cells and Foxp3 + regulatory $\mathbf{T}$ cells. Staining was performed according to our previous publications. ${ }^{19}$ Briefly, after antigen unmasking and blocking, goat antimouse CD $3 \varepsilon$ antibody (Santa Cruz Biotechnology, Santa Cruz, Calif) and polyclonal rabbit antimouse Foxp3 primary antibody (Abcam Inc, Cambridge, Mass) were used to detect CD3+ T cells and CD4+/ $\mathrm{CD} 25+/$ Foxp3 + regulatory $\mathrm{T}$ cells. After incubation with biotin-SPconjugated secondary antibodies and an avidin-biotin complex (Vectastain ABC kit, Vector Laboratories, Burlingame, Calif), immunoreactivity was visualized by incubating the sections with 3,3-diaminobenzidine tetrahydrochloride (DAKO Corporation, Carpinteria, Calif) to produce a brown precipitate, and counterstained with hematoxylin. The infiltrated CD3+ $\mathrm{T}$ cells and Foxp3+ regulatory $\mathrm{T}$ cells were counted and used for statistical analysis.

The number of positive stained cells (neutrophils, macrophages, CD3+ $\mathrm{T}$ cells, and Foxp3 + regulatory $\mathrm{T}$ cells) per high-power field was assessed via immunohistochemical staining of tracheal sections; 4 fields were counted per trachea. To ensure the validity of all cell counts, counting of positively stained cells was performed in a blind manner by a separate investigator. The average cell number was used for statistical analysis.

Immunofluorescence staining of tumor protein P63 and cytokeratin 14. The immunofluorescence staining of $P 63$ and cytokeratin 14 (CK14) was performed according as described previously. ${ }^{21}$ Briefly, paraffin sections were deparaffinized, rehydrated, and stained overnight at $4^{\circ} \mathrm{C}$ with rabbit antimouse P63 (1:750) and guinea pig antimouse CK14 (1:200) (Lifespan BioSciences Inc, Seattle, Wash). Purified normal rabbit and guinea pig IgGs were used as negative controls. Secondary fluorescein isothiocyanate-conjugated donkey antirabbit IgG and Cy5-conjugated goat antiguinea pig IgG were subsequently applied at a 1:2000 dilution for 1 hour at room temperature. The cell nucleus was stained with 4,6-diamidine2-phenylindole dihydrochloride (DAPI; Roche Diagnostics, Mannheim, Germany). Images were viewed and saved using an Olympus BX51 microscope equipped with an Olympus DP70 digital camera (Minneapolis, Minn).

Immunocytochemical staining of human HLA-ABC in PMSCs. Immunocytochemical staining was performed according to our previous publication. ${ }^{21}$ Briefly, PMSCs were fixed in 50\% methanol/ $50 \%$ acetone for 15 minutes and permeated with $1 \%$ Triton $\mathrm{X}-100$ in Tris-buffered saline for 15 minutes. Nonspecific antibody binding in cells was blocked with blocking buffer $(5 \%$ nonfat milk and $10 \%$ normal donkey serum in Tris-buffered saline with $0.1 \%$ Tween-20) for 1 hour at room temperature before overnight incubation with specific rabbit antihuman HLA-ABC antibody (Abcam) in the same buffer $(4 \mu \mathrm{g} / \mathrm{mL})$ at $4{ }^{\circ} \mathrm{C}$. Cells were then incubated with alkaline phosphatase-conjugated secondary antibody (Jackson ImmunoResearch, West Grove, Pa) diluted (1:2000) in blocking buffer for 1 hour at room temperature. The signals were detected by adding Fast Red. Purified preimmune IgGs from the same animal were used as negative controls. The sections were counterstained lightly with hematoxylin and DAPI $(1 \mu \mathrm{g} / \mathrm{mL})$ for viewing negatively stained cells.

\section{Measurement of Tracheal Luminal Obliteration}

Allograft tracheal tissue was fixed, embedded, sectioned, and stained with H\&E. Allograft trachea sections were photographed at $4 \times$ magnification. The luminal obliteration was semiquantified using ImageJ software as described in our previous publications in a blinded fashion. ${ }^{19,20}$ Six to 20 allografts were measured in each group.

\footnotetext{
Statistical Analysis

Statistical differences between 2 groups were determined using the Student $t$ test. Data were reported as the mean \pm standard error of the mean.
}

\section{RESULTS \\ Injection of PMSCs and PMSCCM Attenuated BO on Day 28}

Intratracheal delivery of PMSCs significantly reduced the development of BO on day $28(65.85 \% \pm 2.99 \%$ vs $95.62 \% \pm 0.76 \%, P=.021$; Figure 1$)$. Furthermore, to explore the effects of PMSC-derived soluble paracrine factors on the development of BO, PMSCCM was injected intratracheally. Intratracheal delivery of PMSCCM showed a trend for reduced development of $\mathrm{BO}$, but this was not significant compared with blank medium controls $(62.09 \% \pm$ $4.24 \%$ vs $82.70 \% \pm 3.04, P=.212$; Figure 1 ). Similar to the results for intratracheal injection, local injection of PMSCs significantly reduced luminal obliteration at 28 days after transplantation $(64.38 \% \pm 8.14 \%$ vs $98.78 \%$ $\pm 3.63 \%, P=.015, \mathrm{n}=8$ tracheas per group) compared with controls injected with PBS (Figure E1).

\section{Injection of PMSCs and PMSCCM Protected Against Epithelial Loss on Day 14}

Our previous publication ${ }^{20}$ reported that secondary loss of luminal epithelial integrity was a key factor preceding BO development. Therefore, the potential function of PMSCs to prevent this secondary epithelial loss was evaluated. The allografts treated with PMSCs were significantly protected against the secondary loss of intraluminal epithelium on day 14 compared with the controls injected with PBS $(17.88 \% \pm 2.82$ vs $98.75 \% \pm 0.24 \%$ circumferential epithelial loss, $P<.001$ ) (Figure E2). The effects of intratracheal treatment with PMSCs and PMSCCM on the integrity of epithelial cells within the allografts were then determined. Both PMSC- and PMSCCM-treated tracheas were significantly protected against the secondary loss of intraluminal epithelium on day 14 compared with the tracheas treated with PBS $(55.68 \% \pm 2.62 \%$ vs $79.98 \% \pm$ $2.43 \%, P=.011)$ or blank medium $(28.51 \% \pm 6.18 \%$ vs $74.84 \% \pm 3.99 \%$ ) (Figure 2).

\section{Injection of PMSCs and PMSCCM Blocked Neutrophil and CD3 + T-Cell Infiltration and Increased Macrophage and Foxp3 + Regulatory T-Cell Infiltration on Day 14}

The effects of PMSCs on the infiltration of inflammatory cells in the allografts were explored. As shown in Figure 3, PMSC-treated samples had significantly less neutrophil infiltration compared with saline controls $(4,982,429 \pm$ $1,245,992$ units vs $11,015,522 \pm 5,113,617, P=.001$ ) on day 14 after tracheal transplantation. In contrast, injection of PMSCs increased macrophage infiltration in the same samples $(18,264,767 \pm 5,949,626$ vs $11,554,467 \pm$ $6,472,769, P=.056)$. Furthermore, PMSC treatment significantly decreased CD3 + T-cell infiltration in the allografts on day $14(83.33 \pm 18.61$ vs $51.25 \pm 17.46, P=.006$, 


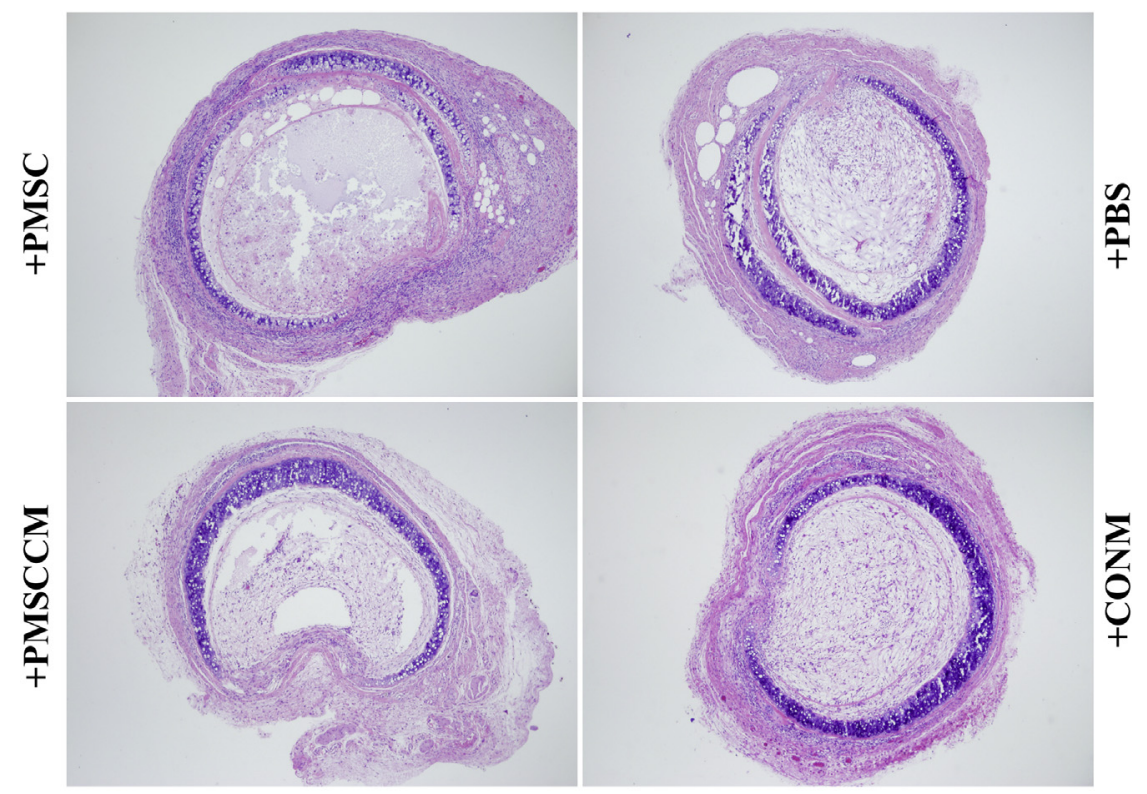

A

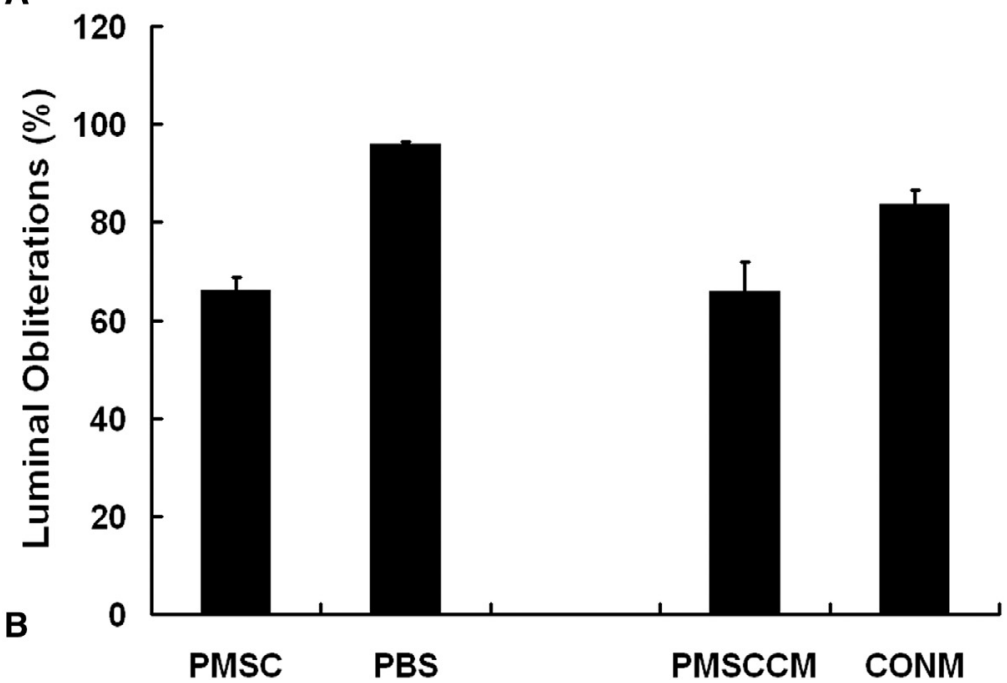

FIGURE 1. Intratracheal injection of PMSCs and PMSCCM attenuated the development of BO on day 28 after tracheal transplantation. A, Representative images of H\&E staining of the allograft 28 days after transplantation. The magnification of all images is $4 \times .+P M S C s$, Treated with PMSCs $\left(1 \times 10^{6}\right)$; $+P B S$, treated with $1 \times$ PBS as the control; + PMSCCM, treated with PMSCCM; + CONM, treated with blank medium as the control. B, Bar graph of luminal obliteration of the allografts with PMSC $(n=13)$ and PMSCCM $(n=8)$ on day 28. Data shown are the mean \pm standard error of mean. PMSC, Placenta-derived human mesenchymal stem cells; PBS, phosphate-buffered saline; PMSCCM, PMSC-conditioned medium; CONM, control media.

Figure E3, A) and markedly enhanced cellular infiltration of Foxp3+ regulatory $\mathrm{T}$ cells on day 14 after tracheal transplantation compared with saline controls $(14.17 \pm 4.96$ vs $21.56 \pm 7.52, P=.036$, Figure E3, $B)$.

\section{Intratracheally Injected PMSCs Did Not Integrate Into the Luminal Epithelial Layer}

We next tried to elucidate whether PMSC engraftment into the luminal epithelium contributed to the epithelial integrity seen with intratracheal injection of PMSCs. Using immunocytochemical staining, we showed that PMSCs are
HLA-ABC positive (Figure 4, A). HLA-ABC staining for the human PMSCs revealed that PMSCs did not integrate into the epithelial layer in this experimental model (Figure 4, B).

\section{Injection of PMSCs and PMSCCM Protected Against Epithelial Loss by Promoting P63 + CK14 + Epithelial Progenitor Cells and Increasing Foxp3+ Regulatory T Cells}

To further explore the mechanism of PMSC protection against epithelial loss, we determined the expression levels 

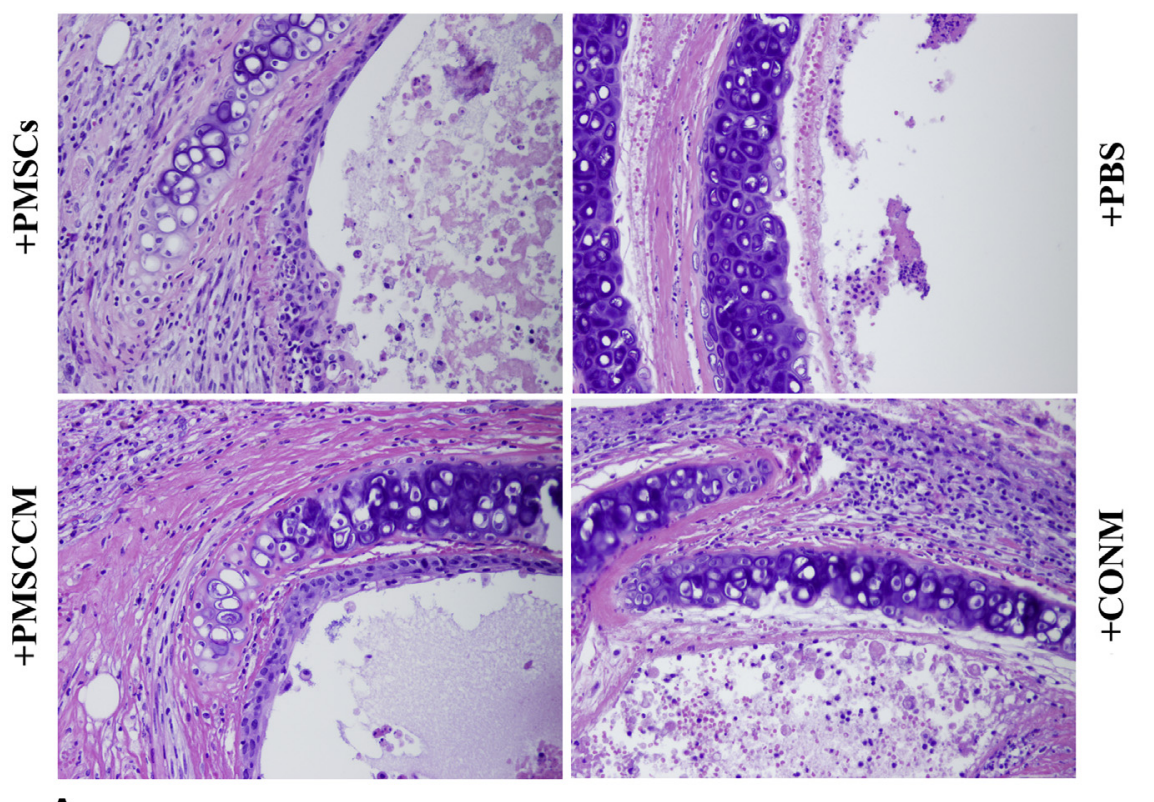

$$
\text { A }
$$

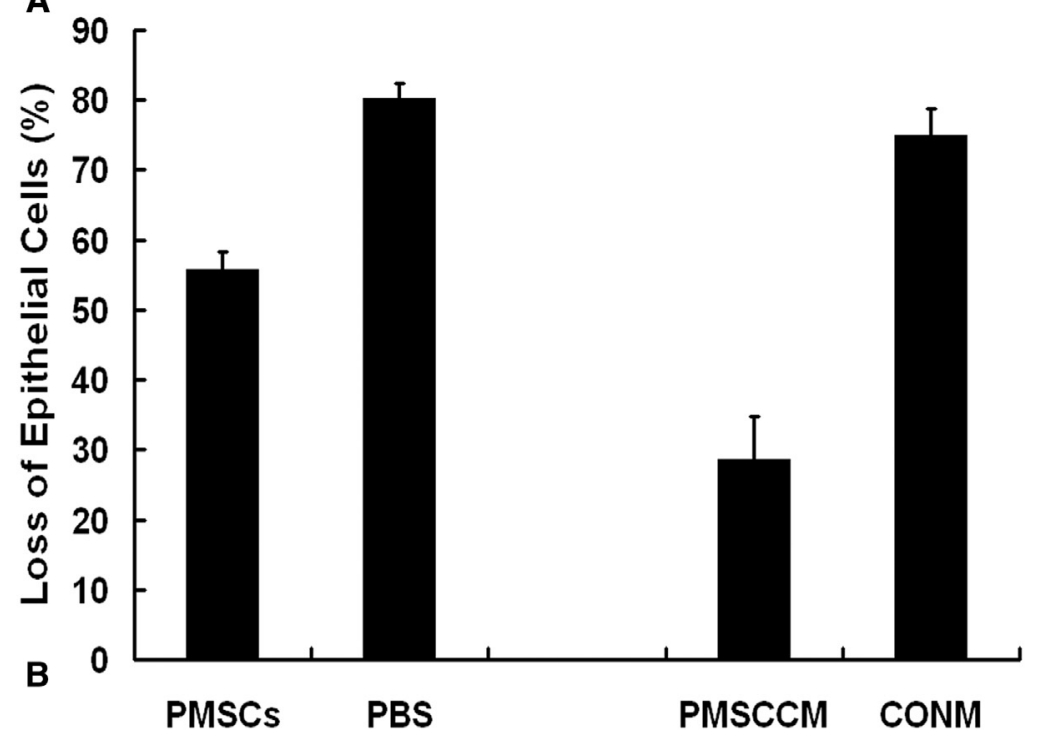

FIGURE 2. Loss of epithelial cells in allografts after intratracheal injection of PMSCs or PMSCCM on day 14 after transplantation. A, Representative images of H\&E-stained histopathologic sections of allografts at 14 days after transplantation. All images are $40 \times$ magnification. $+P M S C s$, Treated with PMSCs $\left(1 \times 10^{6}\right) ;+P B S$, treated with $1 \times$ PBS as control; $+P M S C C M$, treated with PMSCCM; $+C O N M$, treated with blank medium as the control. B, Bar graph depicting percentage allograft luminal epithelial loss with each type of injection ( $n=7-13)$. Data shown are the mean \pm standard error of mean. PMSC, Placenta-derived human mesenchymal stem cells; PBS, phosphate-buffered saline; PMSCCM, PMSC-conditioned medium; CONM, control media.

of 2 epithelial progenitor cell markers: tumor protein P63 and CK14, within the PMSC-treated and saline-treated allografts using immunofluorescence staining. Both P63 and CK14 are believed to be markers of basal epithelial progenitor cells found within mouse and human trachea and lung, ${ }^{22,23}$ As shown in Figure 5 and Figure E4, intratracheal administration of PMSCs and PMSCCM obviously increased P63 and CK14 double-positive cells compared with PBS or blank medium controls. In addition, administration of PMSCs and PMSCCM increased Foxp3+ regulatory $\mathrm{T}$ cells compared with PBS or blank medium controls $(14.08 \pm 2.31$ vs $6.75 \pm 2.49, P<.001)$ (Figure E5).

\section{DISCUSSION}

The importance of bone marrow-derived MSCs in acute lung injury has been well documented in in vitro, ex vivo, and in vivo models. ${ }^{3-11}$ Because ischemia-reperfusion injury is one of the major contributors for the development of $\mathrm{BO}^{1,24}$ and PMSCs showed similar characteristics and 

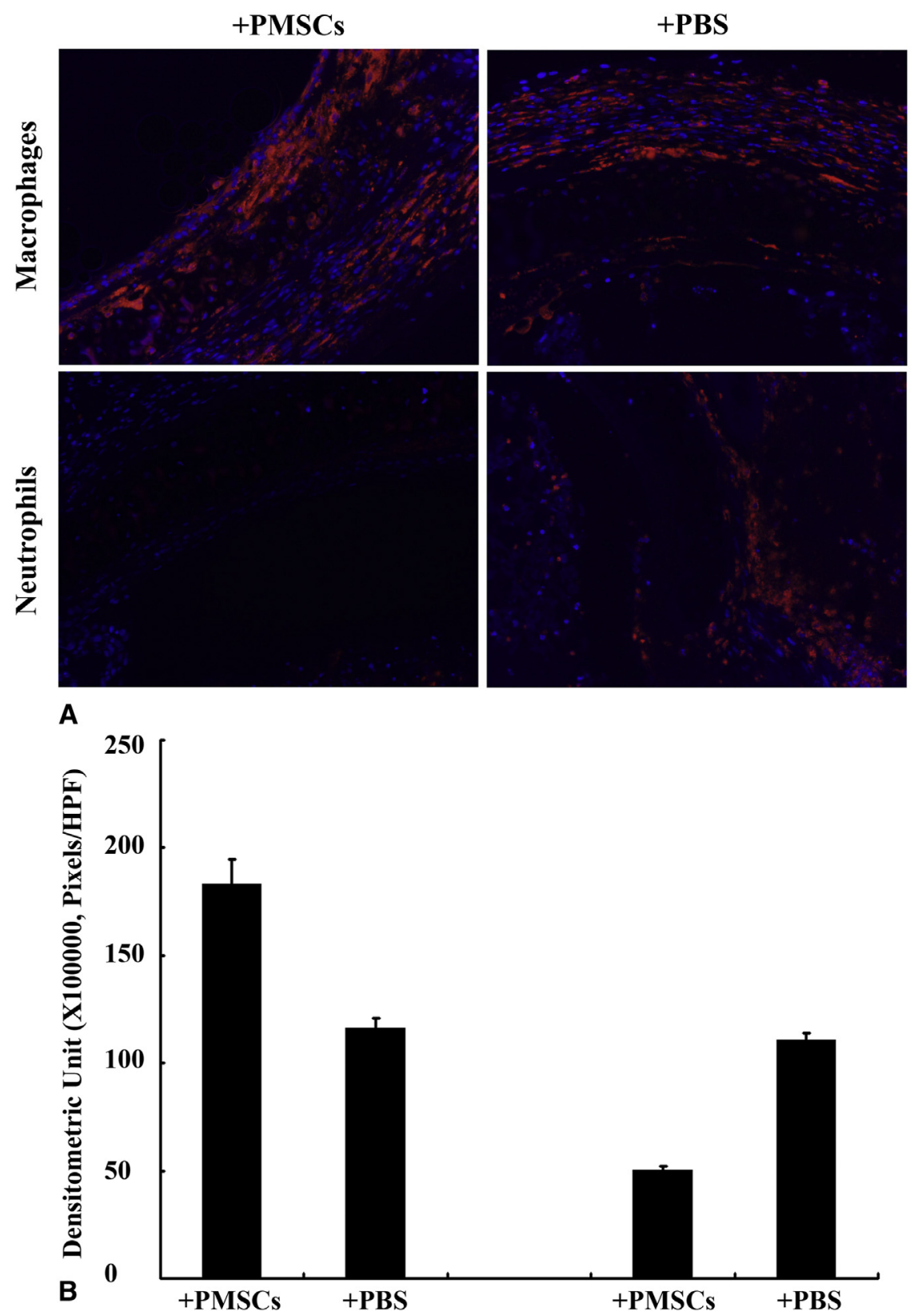

FIGURE 3. Immunofluorescent staining and densitometric analysis of macrophage and neutrophil infiltration in the allografts treated with PMSCs and PBS controls on day 14. A, Representative images of immunofluorescent staining of the allograft 14 days after transplantation. Red color indicates positivestaining signals. Blue color indicates nuclei stained with DAPI. The magnification of all images is $20 \times$. B, Bar graph of macrophage and neutrophil infiltration in the allografts treated with PMSCs and PBS on day 14. Data shown are the mean \pm standard error of mean. $\mathrm{n}=8$. $+P M S C s$, Treated with PMSCs $\left(1 \times 10^{6}\right) ;+P B S$, treated with $1 \times$ PBS as control; $H P F$, high-power field; $P M S C$, placenta-derived human mesenchymal stem cells; $P B S$, phosphatebuffered saline.

effects as the bone marrow-derived MSCs, we tested the hypothesis that PMSCs may halt progression towards luminal obliteration in a well-established mouse HTT model. The results demonstrated that PMSCs indeed attenuated the development of $\mathrm{BO}$ on day 28 after tracheal transplantation compared with control groups. This study is the first to show that PMSCs and PMSCCM attenuate the development of $\mathrm{BO}$ through, at least in part, protection of epithelial integrity at the cellular level. Recently, Grove and colleagues ${ }^{25}$ performed a similar study to investigate treatment with bone marrow-derived MSCs via retroocular injection in the HTT model. In concordance with our results, they found a reduction in intraluminal collagen deposition after treatment with bone marrow-derived MSCs, as well as a reduction in transforming growth factor $\beta$ levels and an increase in IL-10 levels. 
Anti-HLA-ABC
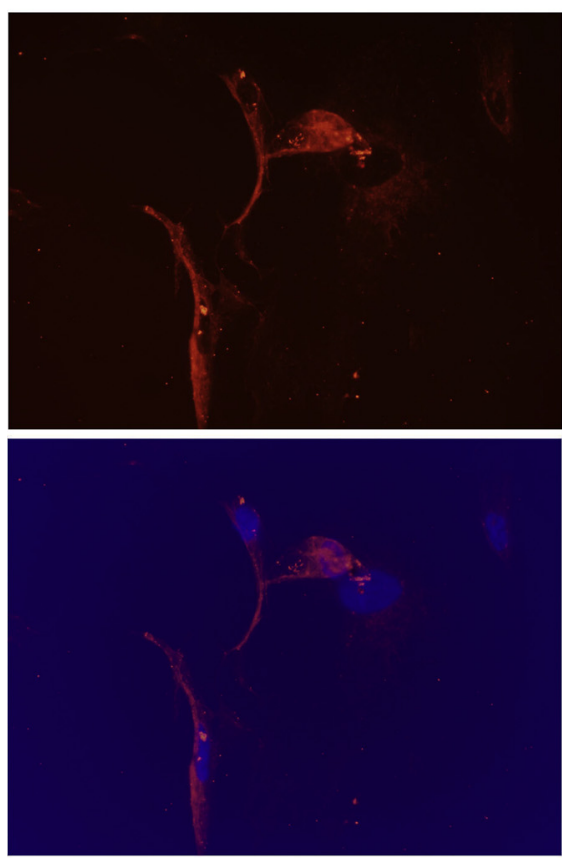

A

Anti-HLA-ABC
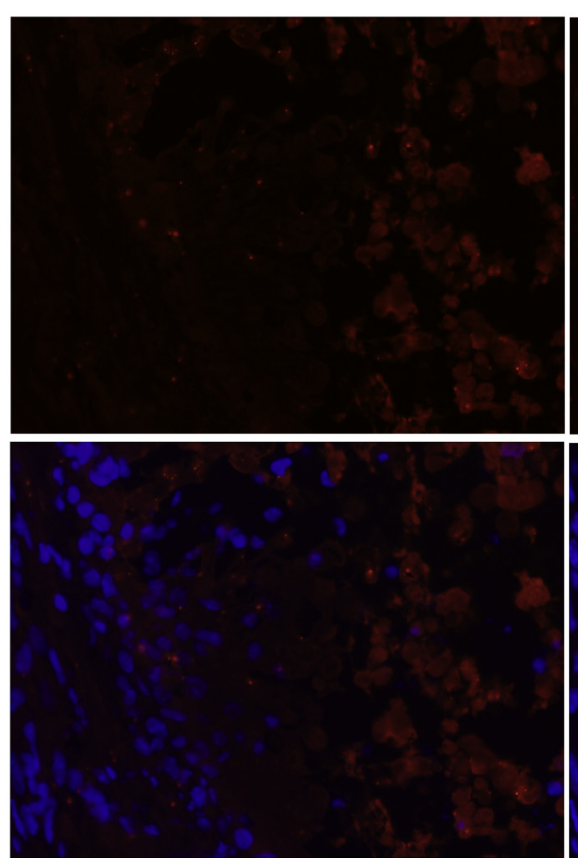

B

FIGURE 4. PMSCs failed to integrate into the airway epithelial layer on day 14 after transplantation after intratracheal delivery. A, Representative images of immunofluorescent staining of human HLA-ABC within in vitro PMSCs. The images were taken at $20 \times$ magnification. Red color indicates positive staining of human HLA-ABC, blue color indicates nuclei stained with DAPI. B, Representative images of immunofluorescent staining of human HLA-ABC and CK14 within tracheas treated with PMSCs. The images were taken at $40 \times$ magnification. Red color indicates positive staining of human HLA-ABC molecules (left panel) and CK14 molecules (right panel); blue color indicates nuclei stained with DAPI. Right, The location of epithelial cells is seen by the area of strong CK14 signal. Left, There is essentially no HLA-ABC signal in this same location. $H L A-A B C$, Human leukocyte antigens-A, -B, and -C. 


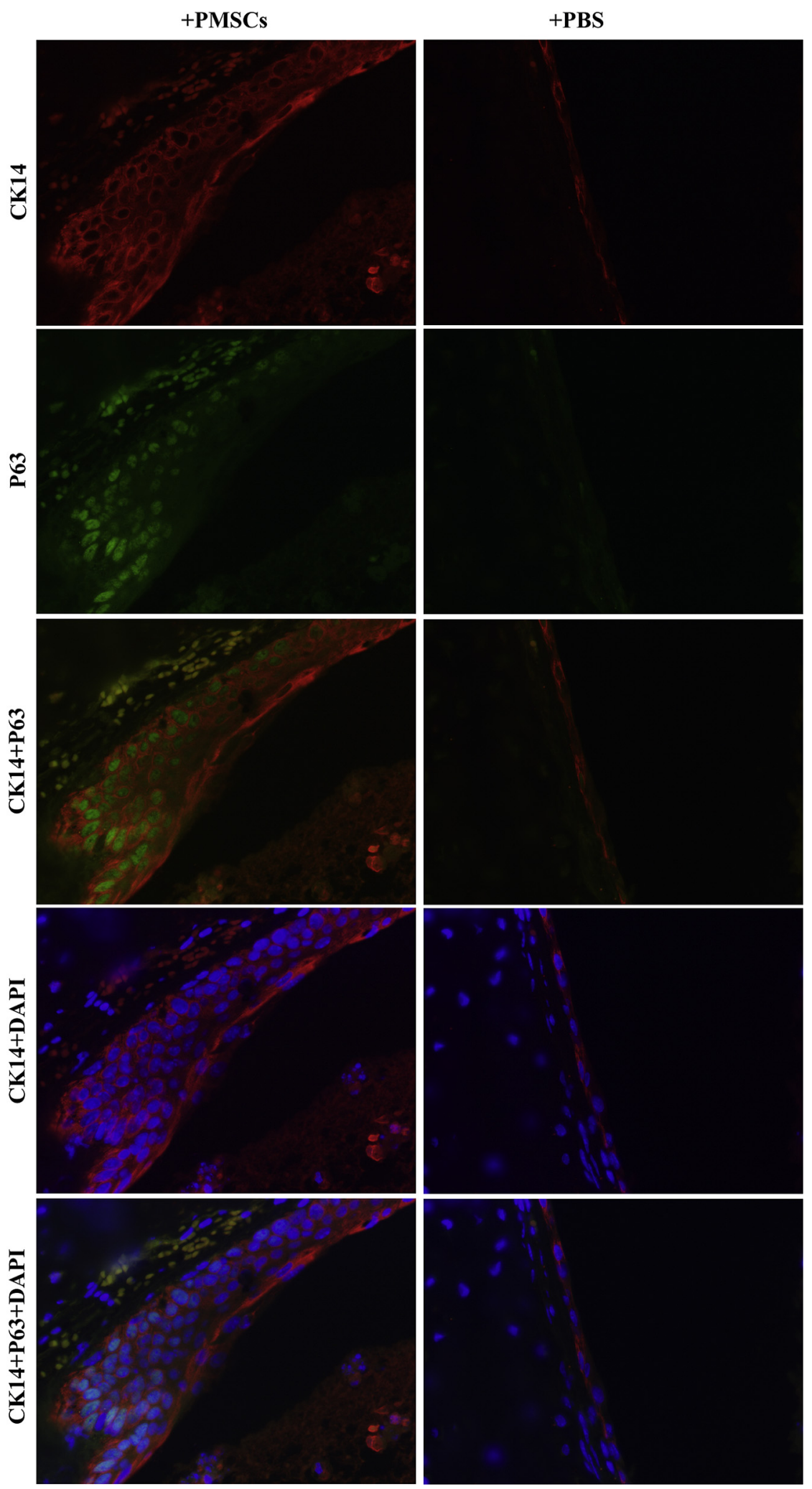

FIGURE 5. Double immunofluorescent staining of P63 and CK14 in the tracheal allografts treated intratracheally with PMSCs or PBS on day 14 after transplantation. Red color indicates positive staining of CK14; green color shows positive staining of P63; blue color indicates nuclei stained with DAPI. The magnification of all images is $40 \times$. The merged images are indicated on the side. $+P M S C s$, Intratracheally treated with PMSCs $\left(1 \times 10^{6}\right)$; $+P B S$, treated with $1 \times$ PBS as control. PMSC, Placenta-derived human mesenchymal stem cells; PBS, phosphate-buffered saline; DAPI, 4,6-diamidine-2-phenylindole dihydrochloride. 
An increase in cells expressing epithelial progenitor cell markers (p63 and CK14) was also seen after PMSC and PMSCCM treatment. Our previous publication ${ }^{20}$ showed that injection of epithelial stem/progenitor cells into the allografts on day 3 after transplantation blocked the loss of epithelial cells within the allografts, which is a key factor for the development of BO. Many different cellular processes have been linked to $\mathrm{p} 63$ regulation in epithelial cells, including cell proliferation, survival, differentiation, apoptosis, cell fate specification, maturation of epithelial progenitor/stem cells, as well as cell-cell and cell-matrix interaction events. ${ }^{22,23}$ Our current results further confirm our previous findings that the integrity of epithelial cells is critical for preventing the progression of BO. These results are in agreement with other publications, showing that epithelial cells play an important role in the development of $\mathrm{BO}^{26,27}$ Therefore, PMSCs and PMSCCM may provide a novel therapeutic strategy to reduce $\mathrm{BO}$ after lung transplantation by promoting epithelial progenitor cells.

Local injection of PMSCs specifically inhibited neutrophil infiltration. Surprisingly, PMSCs increased macrophage infiltration under the same treatment. A recent publication showed that lung-resident tissue macrophages generate Foxp $3+$ regulatory $\mathrm{T}$ cells and promote airway tolerance. ${ }^{28}$ Moreover, injection of PMSCCM also had similar effects on neutrophil infiltration compared with injection of PMSCs. Using a bleomycin-induced lung injury model, Ortiz and colleagues ${ }^{3,8}$ found that MSCs protect lung tissue from injury by blocking TNF- $\alpha$ and IL-1. Xu and colleagues ${ }^{4}$ also showed that MSCs prevented endotoxin-induced lung inflammation, injury, and edema. Several mouse injury models $^{5,8}$ have shown that PMSC treatment affects the secretion of antiinflammatory cytokines, such as IL-1RA, IL-10, and angiopoietin-1. Therefore, a single injection of PMSCCM may reduce proinflammatory cytokines, which subsequently leads to less infiltration of inflammatory cells and immune cells. We have shown that $\mathrm{T}$ cells are critical for epithelial protection, because secondary loss of epithelium does not occur in the HTT model. ${ }^{20}$ Our previous publication showed that loss of epithelium is another essential factor for the development of $\mathrm{BO} .^{20}$ Because the half-life of cytokines is generally short, PMSCCMs were collected just before injection. Therefore, it is highly possible that a single injection of PMSCs/PMSCCM acts as an initiator to start this cascade of processes.

To further elucidate the possibility that PMSCs may successfully engraft into regenerated luminal tracheal epithelium, PMSCs were injected intratracheally on day 3, which is a critical time window for epithelial regeneration. As shown in Figure 5, the intratracheal injection of PMSCs did not engraft into the epithelial layer of allografts in this model. In contrast to our findings, Zhen and colleagues ${ }^{29}$ and Yamada and colleagues ${ }^{6}$ found that MSCs were able to engraft in recipient lungs and differentiate into type II alveolar epithelial cells. These results strongly suggest that PMSCs and PMSCCM may have effects on epithelial maintenance and the development of $\mathrm{BO}$ through a paracrine mechanism rather than direct engraftment. Because the treatment with PMSCs can be substituted with PMSCCM, which contains many biological factors (such as cytokines, growth factors, and so forth), it will be much easier to apply to patients after lung transplantation by inhaling or pretreating the donor lung before the transplantation.

Using a mouse HTT model with Rag-1 KO mice, we have shown that immune cell-mediated activity was key in the secondary loss of epithelial cells. ${ }^{20}$ With this knowledge, we next explored the potential function of PMSCs/PMSCCM as an immune modulator and/or regulator during BO formation. The results demonstrate that intratracheal injection of PMSCs and PMSCCM significantly suppress CD3+ T-cell infiltration on day 14 after tracheal transplantation. These results suggest that PMSCs and PMSCCM may act as an immunosuppressor during the cellular infiltration phase of $\mathrm{BO}$ development. Several publications have suggested that PMSCs have the ability to suppress T-cell proliferation and activation. $^{15-17,30,31}$ Furthermore, recent findings indicate that PMSCs can regulate the secretion of IL-17, ${ }^{18,30}$ an important cytokine secreted by $\mathrm{T}$ cells. Recent data have implicated IL-17 and Th17 cells in the development of autoimmunity and chronic rejection after lung transplantation in animal models and in humans. ${ }^{32,33}$ Based on these reports and our current findings, we suggest that PMSCs may be a novel cell-based therapy for preventing/treating chronic rejection after lung transplantation.

Our current findings show that administration of PMSCs and PMSCCM produced an increase in Foxp3+ regulatory $\mathrm{T}$ cells. Bharat and colleagues ${ }^{34}$ showed that regulatory $\mathrm{T}$ cells limited Th1-autoimmunity by inducing IL-10-producing $\mathrm{T}$ cells after human lung transplantation. ${ }^{34}$ More recent data provide evidence that $\mathrm{CD} 4+$ Foxp3 + regulatory $\mathrm{T}$ cells attenuate $\mathrm{BO}$ through the inhibition of effector $\mathrm{T}$ cells and their function in a rat trachea transplantation model. ${ }^{35}$ Our current data show that PMSC treatment increases macrophage infiltration in the allografts. It is highly possible that increase in Foxp3+ regulatory $\mathrm{T}$ cells may be, at least partially, related to the increase in macrophage infiltration. In combination with our current results, we believe that PMSCs reduce the development of BO not only through suppression of $\mathrm{CD} 3+\mathrm{T}$-cell infiltration but also through stimulating CD4+ Foxp3+ regulatory T cells.

Extrapolating the these findings in the HTT model to application in lung transplant patients, we believe that intratracheal injection of PMSCs or PMSCCM would be roughly comparable to an inhaled nebulized treatment in humans. Although the HTT model is not a perfect representation of this delivery mechanism, the observed effects with direct 
local administration are promising. Intravenous administration of PMSCs or PMSCCM, as studied in the HTT model by Grove and colleagues, ${ }^{25}$ would be the other most logical method of treatment. Despite the advantages discussed earlier, there are some limiting factors to the clinical use of these cells in patients. One of the barriers is the lack of general consensus on a definition of these cells before applying them to patients. Another barrier is the technical difficulties in generating homogeneous lots because of different cell sources and methods of isolation, sorting, culturing, and characterizing. How the effects are evaluated after administering the PMSCs is another challenge that needs to worked out before using these cells clinically.

In summary, PMSCs have various characteristics similar to bone marrow-derived MSCs, including the abilities to protect against epithelial loss through promoting epithelial progenitor cells, regulate inflammatory responses through inhibition of neutrophil infiltration, to modulate immune reaction through decreasing CD3+ T-cell infiltration, and increase immune tolerance through inducing regulatory T-cell production. All these events are important for the development of BO. Therefore, PMSCs may provide a unique and novel treatment option to prevent chronic rejection after lung transplantation.

\section{References}

1. Fiser SM, Tribble CG, Long SM, Kaza AK, Kern JA, Jones DR, et al. Ischemiareperfusion injury after lung transplantation increases risk of late bronchiolitis obliterans syndrome. Ann Thorac Surg. 2002;73:1041-7.

2. Chan A, Allen R. Bronchiolitis obliterans: an update. Curr Opin Pulm Med. 2004; 10:133-41.

3. Ortiz LA, Gambelli F, McBride C, Gaupp D, Baddoo M, Kaminski N, et al. Mesenchymal stem cell engraftment in lung is enhanced in response to bleomycin exposure and ameliorates its fibrotic effects. Proc Natl Acad Sci U S A. 2003; 100:8407-11.

4. Xu J, Woods CR, Mora AL, Joodi R, Brigham KL, Iyer S, et al. Prevention of endotoxin-induced systemic response by bone marrow-derived mesenchymal stem cells in mice. Am J Physiol Lung Cell Mol Physiol. 2007;293:L131-41.

5. Gupta N, Su X, Popov B, Lee JW, Serikov V, Matthay MA. Intrapulmonary delivery of bone marrow-derived mesenchymal stem cells improves survival and attenuates endotoxin-induced acute lung injury in mice. J Immunol. 2007;179:1855-63.

6. Yamada M, Kubo H, Kobayashi S, Ishizawa K, Numasaki M, Ueda S, et al. Bone marrow-derived progenitor cells are important for lung repair after lipopolysaccharide-induced lung injury. J Immunol. 2004;172:1266-72.

7. Lee JW, Fang X, Krasnodembskaya A, Howard JP, Matthay MA. Concise review: Mesenchymal stem cells for acute lung injury: role of paracrine soluble factors. Stem Cells. 2011;29:913-9.

8. Ortiz LA, Dutreil M, Fattman C, Pandey AC, Torres G, Go K, et al. Interleukin 1 receptor antagonist mediates the antiinflammatory and antifibrotic effect of mesenchymal stem cells during lung injury. Proc Natl Acad Sci U S A. 2007; 104:11002-7.

9. Rojas M, Xu J, Woods CR, Mora AL, Spears W, Roman J, et al. Bone marrowderived mesenchymal stem cells in repair of the injured lung. Am J Respir Cell Mol Biol. 2005;33:145-52.

10. Glennie S, Soeiro I, Dyson PJ, Lam EW, Dazzi F. Bone marrow mesenchymal stem cells induce division arrest anergy of activated T cells. Blood. 2005;105:2821-7.

11. Beyth S, Borovsky Z, Mevorach D, Liebergall M, Gazit Z, Aslan H, et al. Human mesenchymal stem cells alter antigen-presenting cell maturation and induce Tcell unresponsiveness. Blood. 2005; 105:2214-9.

12. Neyrinck AP, Lee JW, Fang X, Gupta N, Matthay MA. Angiopoietin-1 reverses protein permeability in an injured model of cultured human alveolar epithelial type II cells. FASEB J. 2008;22:932.6.
13. Vellasamy S, Sandrasaigaran P, Vidyadaran S, George E, Ramasamy R. Isolation and characterisation of mesenchymal stem cells derived from human placenta tissue. World J Stem Cells. 2012;4:53-61.

14. Abumaree MH, Al Jumah MA, Kalionis B, Jawdat D, Al Khaldi A, AlTalabani AA et al. Phenotypic and functional characterization of mesenchymal stem cells from chorionic villi of human term placenta. Stem Cell Rev. 2013;9:16-31.

15. Luan X, Li G, Wang G, Wang F, Lin Y. Human placenta-derived mesenchymal stem cells suppress $\mathrm{T}$ cell proliferation and support the culture expansion of cord blood CD34+ cells: a comparison with human bone marrow-derived mesenchymal stem cells. Tissue Cell. 2013;45:32-8.

16. Liu KJ, Wang CJ, Chang CJ, Hu HI, Hsu PJ, Wu YC, et al. Surface expression of HLA-G is involved in mediating immunomodulatory effects of placenta-derived multipotent cells (PDMCs) towards natural killer lymphocytes. Cell Transplant. 2011;20:1721-30.

17. Yuan W, Zong C, Huang Y, Gao Y, Shi D, Chen C, et al. Biological, immunological and regenerative characteristics of placenta-derived mesenchymal stem cell isolated using a time-gradient attachment method. Stem Cell Res. 2012;9:110-23.

18. Sharma AK, Lu G, Jester A, Johnston WF, Zhao Y, Hajzus VA, et al. Experimental abdominal aortic aneurysm formation is mediated by IL-17 and attenuated by mesenchymal stem cell treatment. Circulation. 2012;126(11 Suppl 1):S38-45. Erratum in: Circulation. 2012;126:e278.

19. Lau CL, Zhao Y, Kron IL, Stoler MH, Laubach VE, Ailawadi G, et al. The role of adenosine A2A receptor signaling in bronchiolitis obliterans. Ann Thorac Surg. 2009;88:1071-8.

20. Zhao Y, Steidle JF, Upchurch GR, Kron IL, Lau CL. Prevention of the second stage of epithelial loss is a potential novel treatment for bronchiolitis obliterans. J Thorac Cardiovasc Surg. 2013;145:940-7.

21. Zhao Y, Sharma AK, LaPar DJ, Kron IL, Ailawadi G, Liu Y, et al. Depletion of tissue plasminogen activator attenuates lung ischemia-reperfusion injury via inhibition of neutrophil extravasation. Am J Physiol Lung Cell Mol Physiol. 2011 300:L718-29.

22. Candi E, Cipollone R, Rivetti di Val Cervo P, Gonfloni S, Melino G, et al. p63 in epithelial development. Cell Mol Life Sci. 2008;65:3126-33.

23. Rock JR, Hogan BL. Epithelial progenitor cells in lung development, maintenance, repair, and disease. Annu Rev Cell Dev Biol. 2011;27:493-512.

24. Bharat A, Narayanan K, Street T, Fields RC, Steward N, Aloush A, et al. Early posttransplant inflammation promotes the development of alloimmunity and chronic human lung allograft rejection. Transplantation. 2007;83:150-8.

25. Grove DA, Xu J, Joodi R, Torres-Gonzales E, Neujahr D, Mora AL, et al. Attenuation of early airway obstruction by mesenchymal stem cells in a murine model of heterotopic tracheal transplantation. J Heart Lung Transplant. 2011;30:341-50.

26. Puchelle E, Peault B. Human airway xenograft models of epithelial cell regeneration. Respir Res. 2000;1:125-8.

27. Qu N, de Vos P, Schelfhorst M, de Haan A, Timens W, Prop J. Integrity of airway epithelium is essential against obliterative airway disease in transplanted rat tracheas. J Heart Lung Transplant. 2005;24:882-90.

28. Soroosh P, Doherty TA, Duan W, Mehta AK, Choi H, Adams YF, et al. Lung-resident tissue macrophages generate Foxp3 + regulatory T cells and promote airway tolerance. J Exp Med. 2013;210:775-88.

29. Zhen G, Liu H, Gu N, Zhang H, Xu Y, Zhang Z. Mesenchymal stem cells transplantation protects against rat pulmonary emphysema. Front Biosci. 2008;13: 3415-22.

30. Wang GY, Zhang SY, Li GY, Wang FF, DU HB, Luan XY. The effect of human placenta-derived mesenchymal stem cells on cord blood CD8(+); T cells activation, cell cycle and secretion of IL-17. Xi Bao Yu Fen Zi Mian Yi Xue Za Zhi. 2012; 28:17-20 [in Chinese].

31. Lee JM, Jung J, Lee HJ, Jeong SJ, Cho KJ, Hwang SG, et al. Comparison of immunomodulatory effects of placenta mesenchymal stem cells with bone marrow and adipose mesenchymal stem cells. Int Immunopharmacol. 2012;13:219-24.

32. Shilling RA, Wilkes DS. Role of Th17 cells and IL-17 in lung transplant rejection. Semin Immunopathol. 2011;33:129-34.

33. Nakagiri T, Inoue M, Minami M, Shintani Y, Okumura M. Immunology minireview: the basics of $\mathrm{T}(\mathrm{H}) 17$ and interleukin-6 in transplantation. Transplant Proc. 2012;44:1035-40.

34. Bharat A, Fields RC, Steward N, Trulock EP, Patterson GA, Mohanakumar T CD4+25+ regulatory T cells limit Th1-autoimmunity by inducing IL-10 producing T cells following human lung transplantation. Am J Transplant. 2006;6:1799-808.

35. Shi Q, Cao H, Liu J, Zhou X, Lan Q, Zheng S, et al. CD4+ Foxp3+ regulatory T cells induced by TGF- $\beta$, IL-2 and all-trans retinoic acid attenuate obliterative bronchiolitis in rat trachea transplantation. Int Immunopharmacol. 2011;11: 1887-94. 


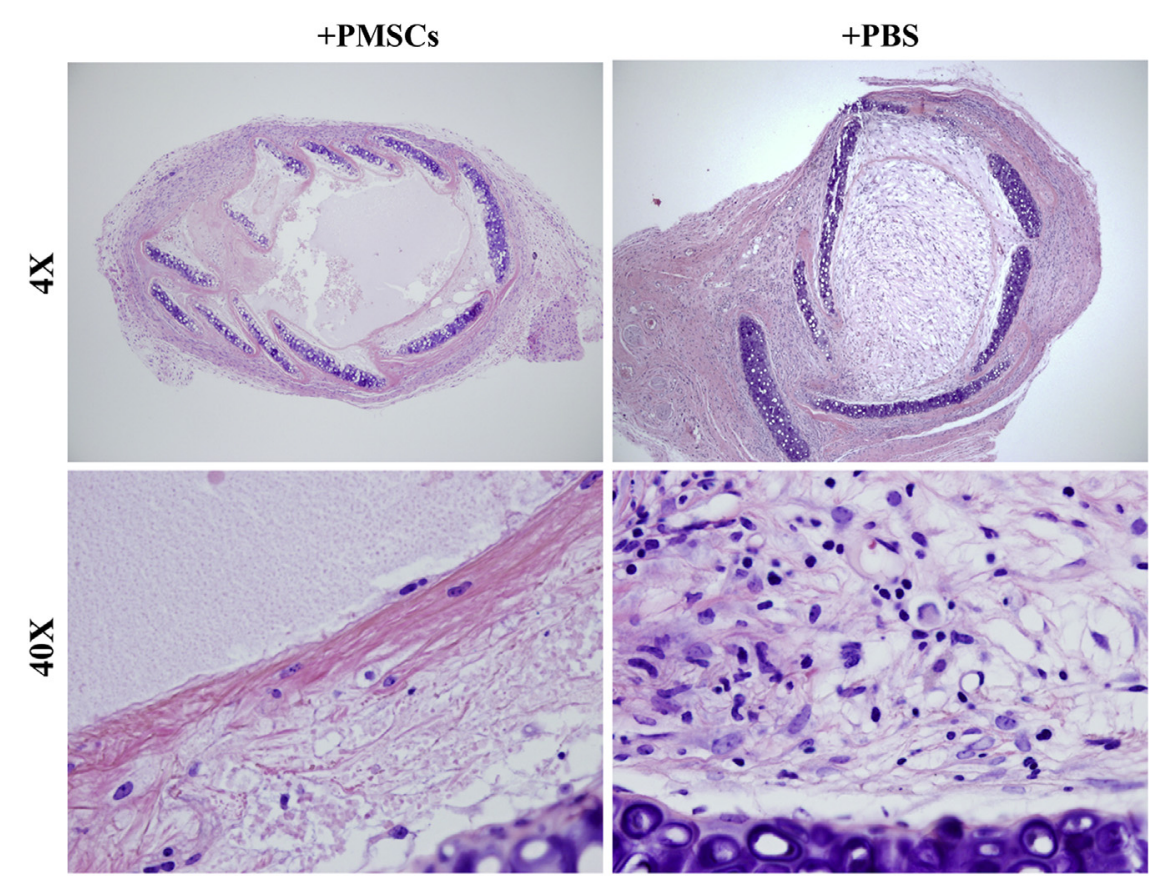

\section{A}

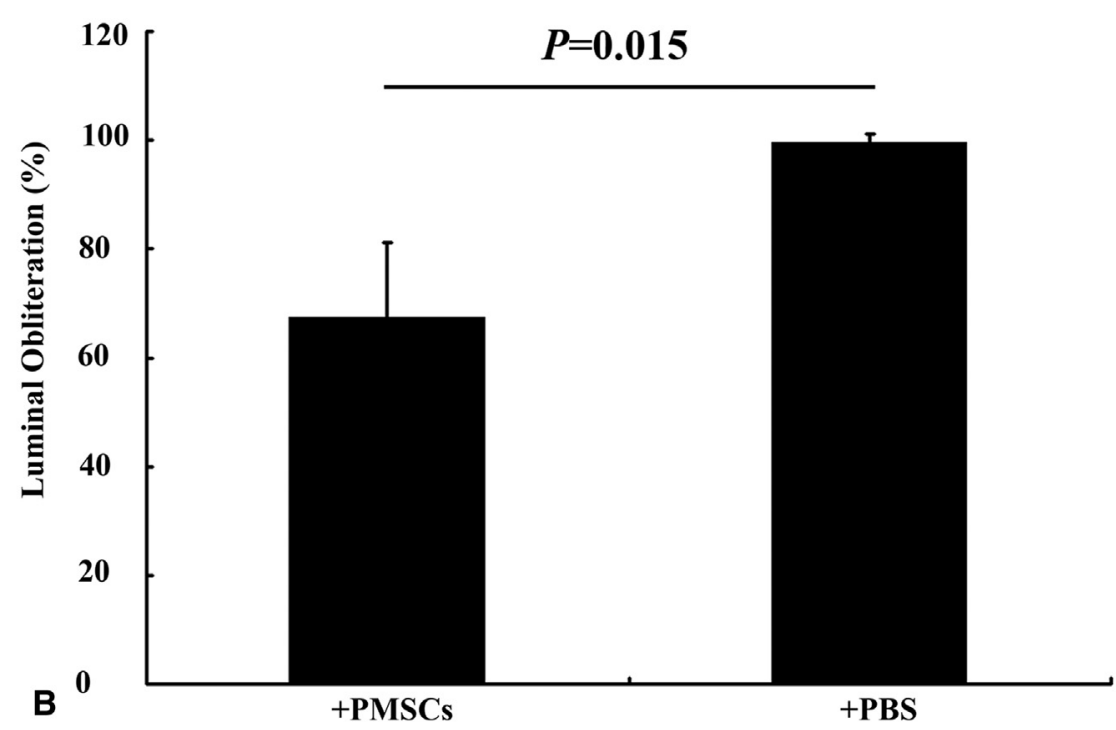

FIGURE E1. Local injection of PMSCs reduced the development of BO on day 28 after tracheal transplantation. A, Representative images of H\&E-stained tracheal allografts 28 days after transplantation. The magnification of the images is indicated on the left. B, Comparison of luminal obliteration of the allografts with and without PMSC injection on day 28. Data shown are the mean \pm standard deviation. $\mathrm{n}=8 .+P M S C s$, Treated with PMSCs $\left(1 \times 10^{6}\right)$; $+P B S$, treated with $1 \times$ PBS as control. PMSC, Placenta-derived human mesenchymal stem cells; $P B S$, phosphate-buffered saline. 

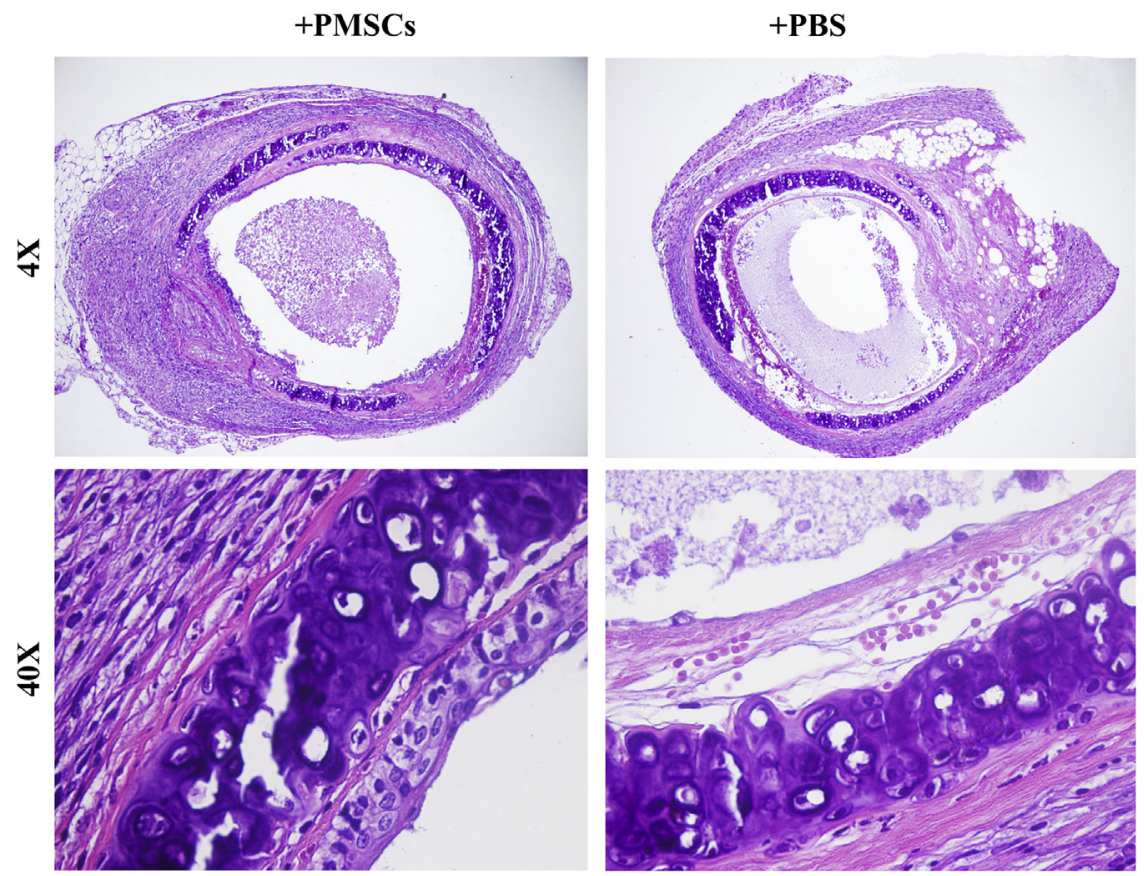

A

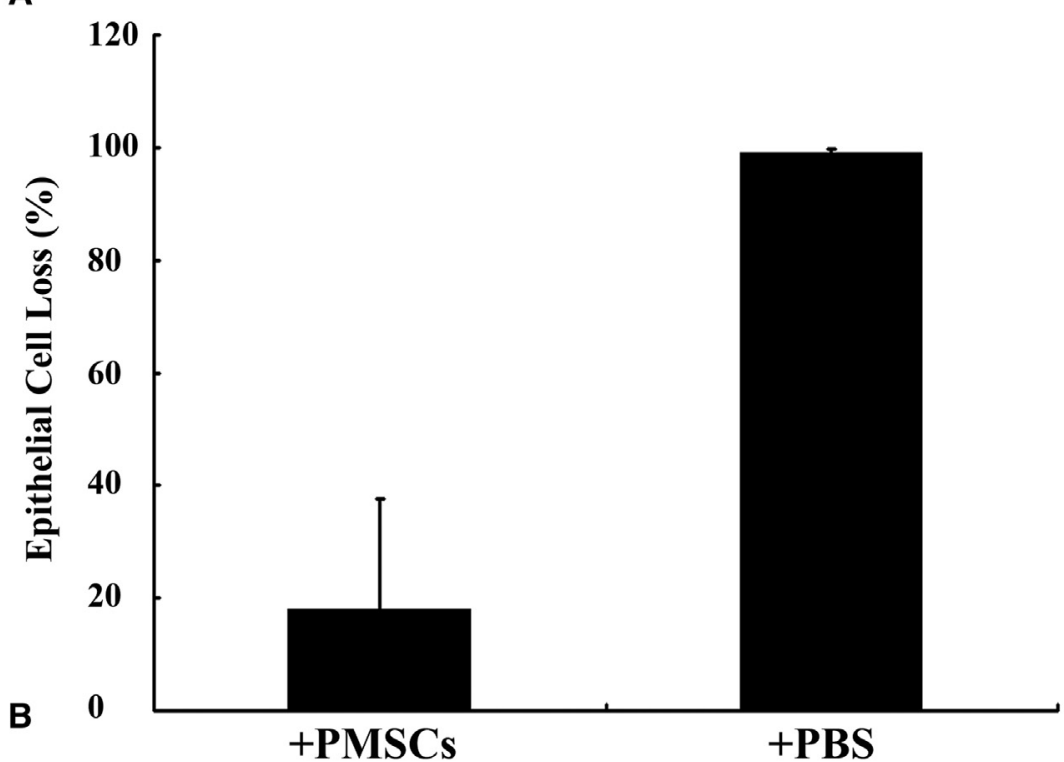

FIGURE E2. Loss of epithelial cells in allografts with and without local PMSC injection on day 14 after transplantation. A, Representative images of H\&E-stained histopathologic sections of tracheas treated with PMSCs (left column) and PBS (right column) at 14 days after transplantation. B, Bar graph of epithelial cell loss in allografts with and without PMSC injection on day 14. Data shown are the mean \pm standard deviation. $n=8$. $+P M S C s$, Intratracheally treated with PMSCs $\left(1 \times 10^{6}\right) ;+P B S$, treated with $1 \times$ PBS as control. PMSC, Placenta-derived human mesenchymal stem cells; $P B S$, phosphate-buffered saline. 

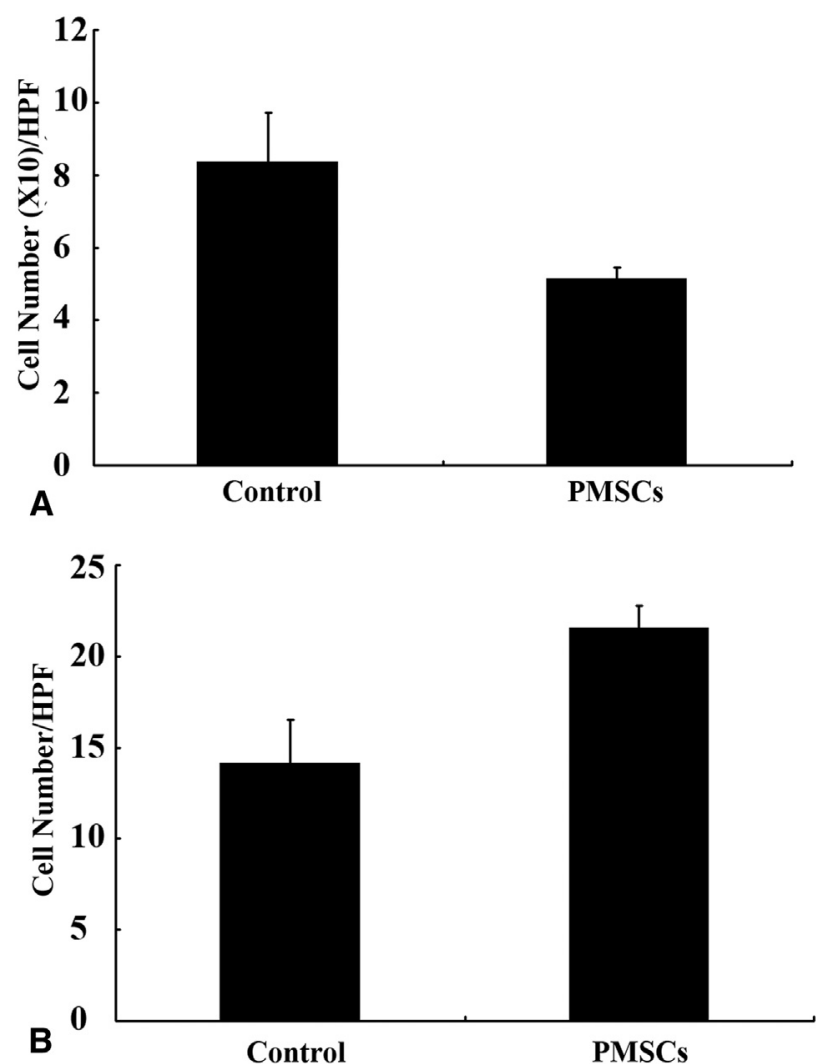

FIGURE E3. Immunohistochemical staining of CD3+ T cells (A) and CD4+ CD25+ Foxp3 + regulatory T cells (B) in the allografts treated with PMSCs and PBS controls on day 14. Data shown are the mean \pm standard error of the mean. $n=8$. HPF, High-power field; PMSC, placenta-derived human mesenchymal stem cells. 
+ PMSCCM

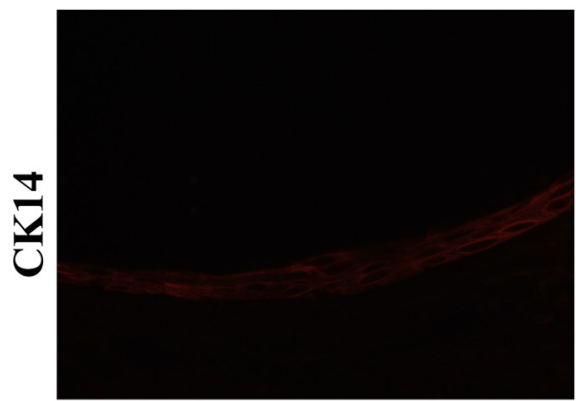

$\dddot{\varkappa}$

6
+
0
0
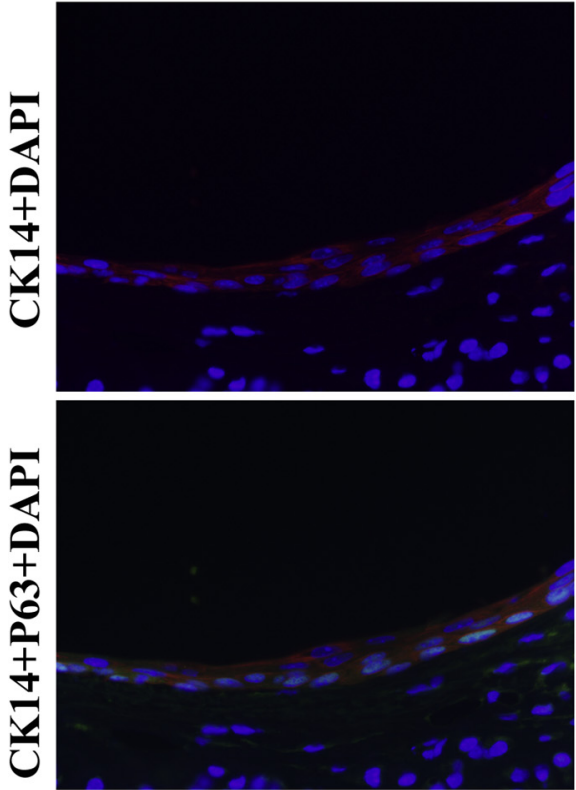

+ CONM
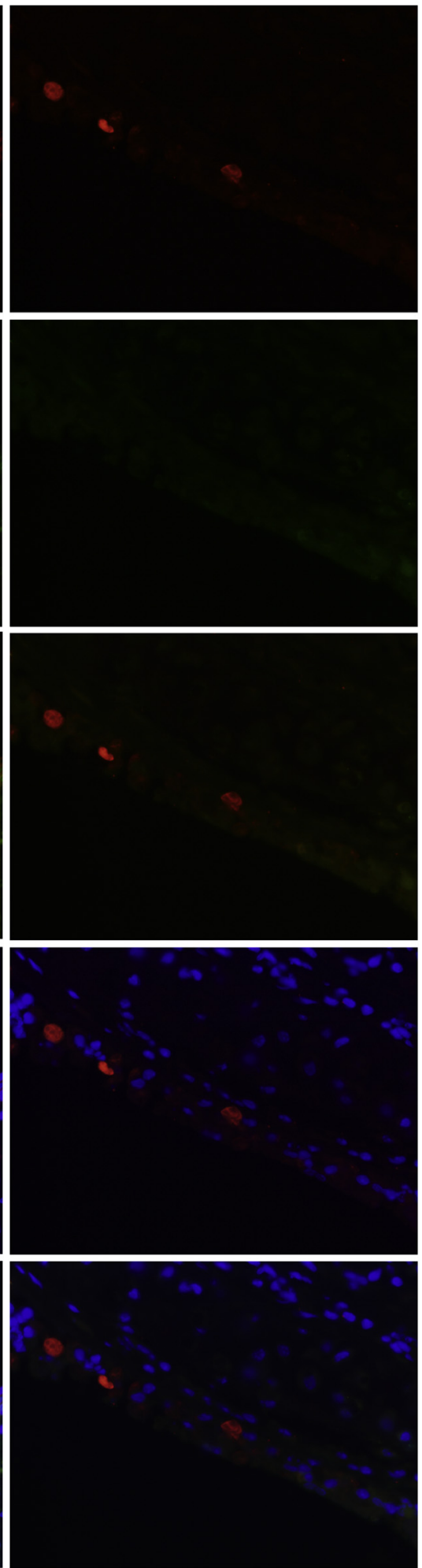

FIGURE E4. Double immunofluorescent staining of P63 and CK14 in the tracheal allografts after intratracheal treatment with PMSCCM or blank medium on day 14 after transplantation. Red color indicates positive staining of CK14; green color shows positive staining of P63; blue color indicates nuclei stained with DAPI. The magnification of all images is $40 \times$. The merged images are indicated on the side $+P M S C C M$, Treated with PMSCCM; + CONM, treated with blank medium as control. DAPI, 4,6-diamidine-2-phenylindole dihydrochloride; PMSCCM, PMSC-conditioned medium; CONM, control media. 

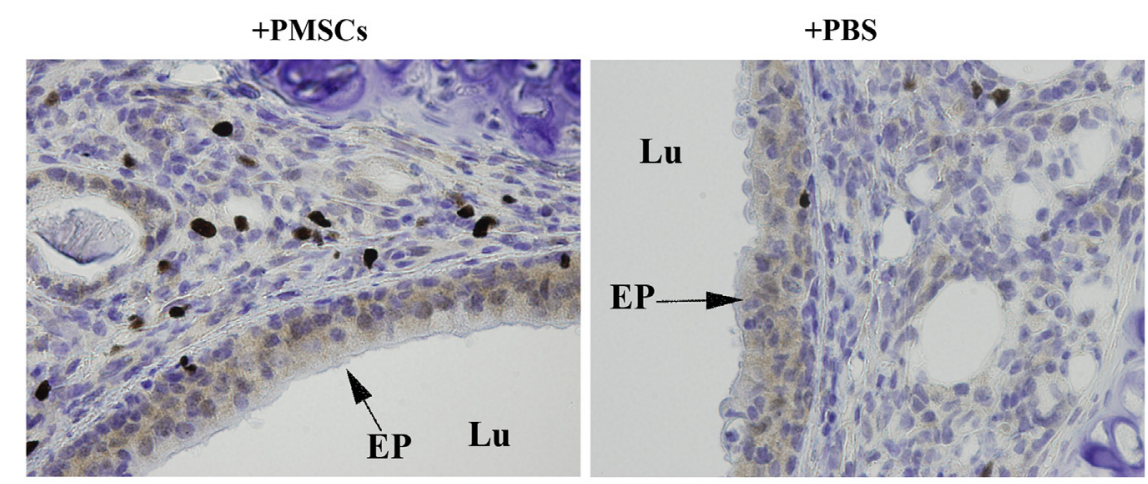

A

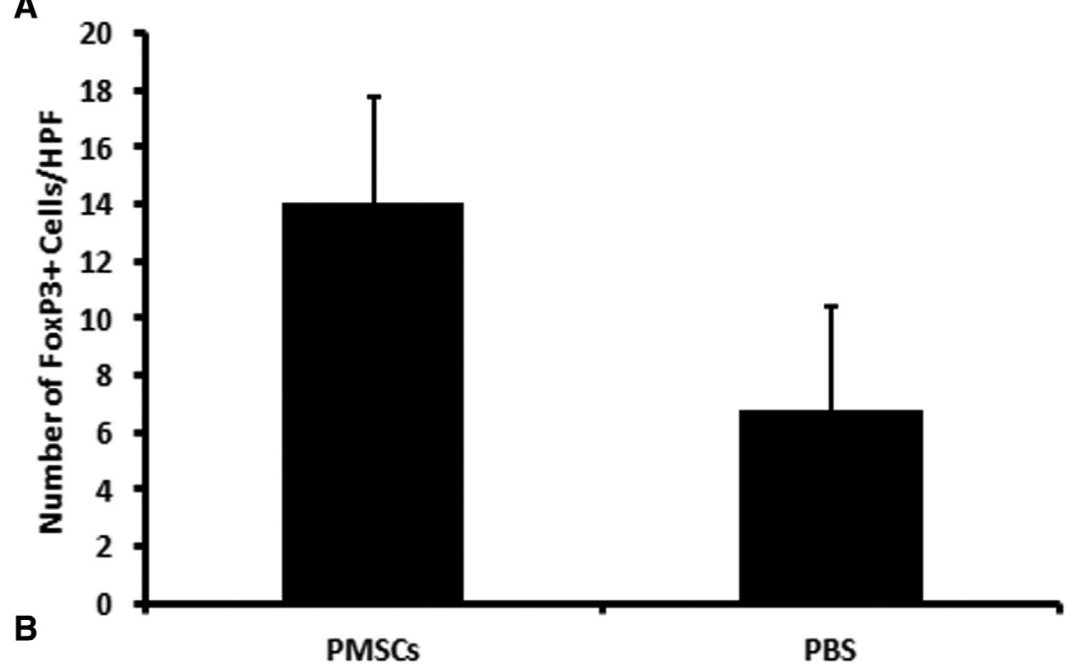

FIGURE E5. Immunohistochemical staining of Foxp3 + regulatory T cells in allografts treated intratracheally with PMSCs and PBS controls on day 7 after transplantation. A, Representative images of immunohistochemical staining of Foxp3+ regulatory $\mathrm{T}$ cells in allografts at 7 days after transplantation. Images are at $40 \times$ magnification. $+P M S C s$, Treated with PMSCs $\left(1 \times 10^{6}\right) ;+P B S$, treated with $1 \times$ PBS as control. B, Bar graph of Foxp3+ regulatory $\mathrm{T}$ cells in the allografts. Data shown are the mean \pm standard error of the mean. $n=8$-12. $L u$, Lumen; $E P$, epithelial layer; $H P F$, high-power field; $P M S C$, placenta-derived human mesenchymal stem cells; $P B S$, phosphate-buffered saline. 